\title{
Derived Crop Management Data for the LandCarbon Project
}

Open-File Report 2011-1303 



\section{Derived Crop Management Data for the LandCarbon Project}

By Gail Schmidt, Shuguang Liu, and Jennifer Oeding

Open-File Report 2011-1303 


\title{
U.S. Department of the Interior \\ KEN SALAZAR, Secretary \\ U.S. Geological Survey \\ Marcia K. McNutt, Director
}

\author{
U.S. Geological Survey, Reston, Virginia: 2011
}

For more information on the USGS - the Federal source for science about the Earth, its natural and living resources, natural hazards, and the environment, visit http://www.usgs.gov or call 1-888-ASK-USGS.

For an overview of USGS information products, including maps, imagery, and publications, visit http://www.usgs.gov/pubprod

To order this and other USGS information products, visit http://store.usgs.gov

Any use of trade, product, or firm names is for descriptive purposes only and does not imply endorsement by the U.S. Government.

Although this report is in the public domain, permission must be secured from the individual copyright owners to reproduce any copyrighted materials contained within this report.

Suggested citation:

Schmidt, Gail, Liu, Shuguang, and Oeding, Jennifer, 2011, Derived crop management data for the LandCarbon Project: U.S. Geological Survey Open-File Report, 2011-1303, 15 p. 


\section{Contents}

Introduction

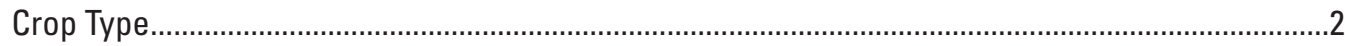

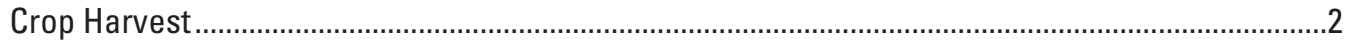

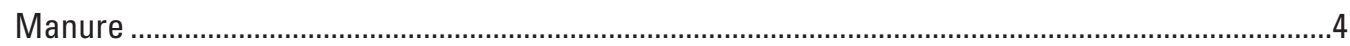

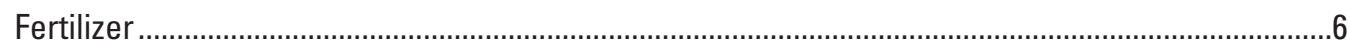

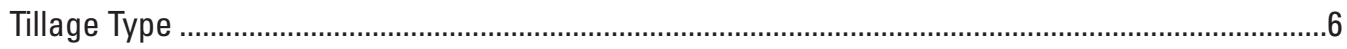

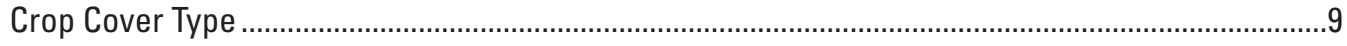

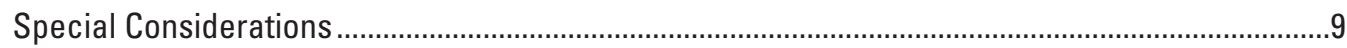

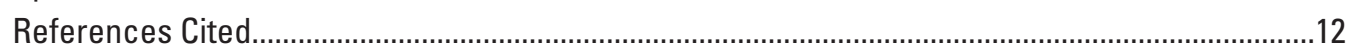

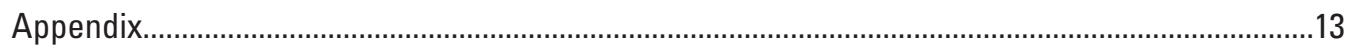

\section{Figures}

1. Map showing derived crop type for Ecoregion 9.2 …….................................................

2. Map showing derived crop harvest for Ecoregion 9.2 ..................................................

3. Map showing derived manure Carbon rates for Ecoregion 9.2 …...................................7

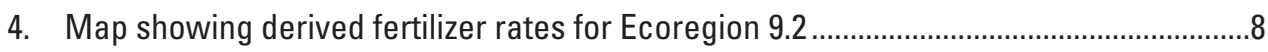

5. Map showing derived tillage types for Ecoregion 9.2 .................................................. 10

6. Map showing derived cover crop for Ecoregion 9.2 ......................................................11

\section{Tables}

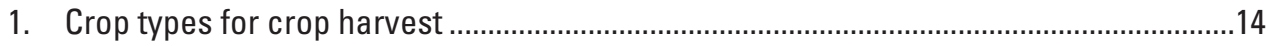

2. Practice types for crop harvest data.............................................................................14

3. Land cover classes used in crop type data.......................................................................14

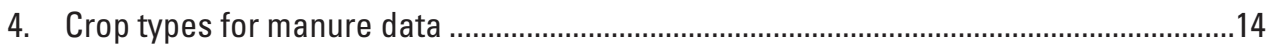

5. Crop types for fertilizer data .............................................................................................

6. Nutrient types for fertilizer data ................................................................................ 14

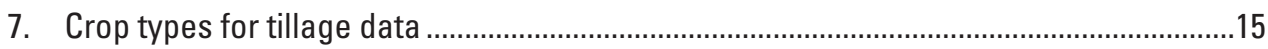

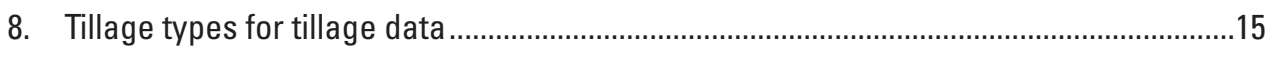

9. Cover crop types for cover crop data .......................................................................... 15 
Conversion Factors and Abbreviations

\begin{tabular}{lcl}
\multicolumn{1}{l}{ Inch/Pound to SI } & \multicolumn{1}{c}{ To obtain } \\
\hline \multicolumn{1}{l}{ Multiply } & By & \\
\hline foot $(\mathrm{ft})$ & 0.3048 & meter $(\mathrm{m})$ \\
yard $(\mathrm{yd})$ & 0.9144 & meter $(\mathrm{m})$ \\
\hline \multicolumn{4}{c}{ Area } & \\
\hline acre & 4,047 & square meter $\left(\mathrm{m}^{2}\right)$ \\
acre & 0.4047 & hectare $($ ha) \\
square foot $\left(\mathrm{ft}^{2}\right)$ & 0.09290 & square meter $\left(\mathrm{m}^{2}\right)$ \\
\hline & Mass & \\
\hline ounce $(\mathrm{oz})$ & 28.35 & gram $(\mathrm{g})$ \\
ounces per square yard $\left(\mathrm{oz} / \mathrm{yd}^{2}\right)$ & 33.9057473586 & grams per square meter $\left(\mathrm{g} / \mathrm{m}^{2}\right)$ \\
\hline
\end{tabular}




\title{
Derived Crop Management Data for the LandCarbon Project
}

\author{
By Gail Schmidt', Shuguang Liu', and Jennifer Oeding'
}

\section{Introduction}

The LandCarbon project is assessing potential carbon pools and greenhouse gas fluxes under various scenarios and land management regimes to provide information to support the formulation of policies governing climate change mitigation, adaptation and land management strategies. The project is unique in that spatially explicit maps of annual land cover and land-use change are created at the 250-meter pixel resolution. The project uses vast amounts of data as input to the models, including satellite, climate, land cover, soil, and land management data. Management data have been obtained from the U.S. Department of Agriculture (USDA) National Agricultural Statistics Service (NASS) and USDA Economic Research Service (ERS) that provides information regarding crop type, crop harvesting, manure, fertilizer, tillage, and cover crop (U.S. Department of Agriculture, 2011a, b, c). The LandCarbon team queried the USDA databases to pull historic crop-related management data relative to the needs of the project. The data obtained was in table form with the County or State Federal Information Processing Standard (FIPS) and the year as the primary and secondary keys. Future projections were generated for the A1B, A2, B1, and B2 Intergovernmental Panel on Climate Change (IPCC) Special Report on Emissions Scenarios (SRES) scenarios using the historic data values along with coefficients generated by the project. The PBL Netherlands Environmental Assessment Agency (PBL) Integrated Model to Assess the Global Environment (IMAGE) modeling framework (Integrated Model to Assess the Global Environment, 2006) was used to develop coefficients for each IPCC SRES scenario, which were applied to the historic management data to produce future land management practice projections.

The LandCarbon project developed algorithms for deriving gridded data, using these tabular management data products as input. The derived gridded crop type, crop harvesting, manure, fertilizer, tillage, and cover crop products are used as

${ }^{1}$ Stinger Ghaffarian Technologies (SGT), contractor to the U.S. Geological Survey, Earth Resources and Observation Science (EROS) Center, 47914 252nd Street, Sioux Falls, SD 57198, USA; worked performed under USGS contract G10PC00044.

${ }^{2}$ U.S. Geological Survey, Earth Resources and Observation Science (EROS) Center, 47914 252nd Street, Sioux Falls, SD 57198, USA. input to the LandCarbon models to represent the historic and the future scenario management data.

The overall algorithm to generate each of the gridded management products is based on the land cover and the derived crop type. For each year in the land cover dataset, the algorithm loops through each 250-meter pixel in the ecoregion. If the current pixel in the land cover dataset is an agriculture pixel, then the crop type is determined. Once the crop type is derived, then the crop harvest, manure, fertilizer, tillage, and cover crop values are derived independently for that crop type. The following is the overall algorithm used for the set of derived grids. The specific algorithm to generate each management dataset is discussed in the respective section for that dataset, along with special data handling and a description of the output product.

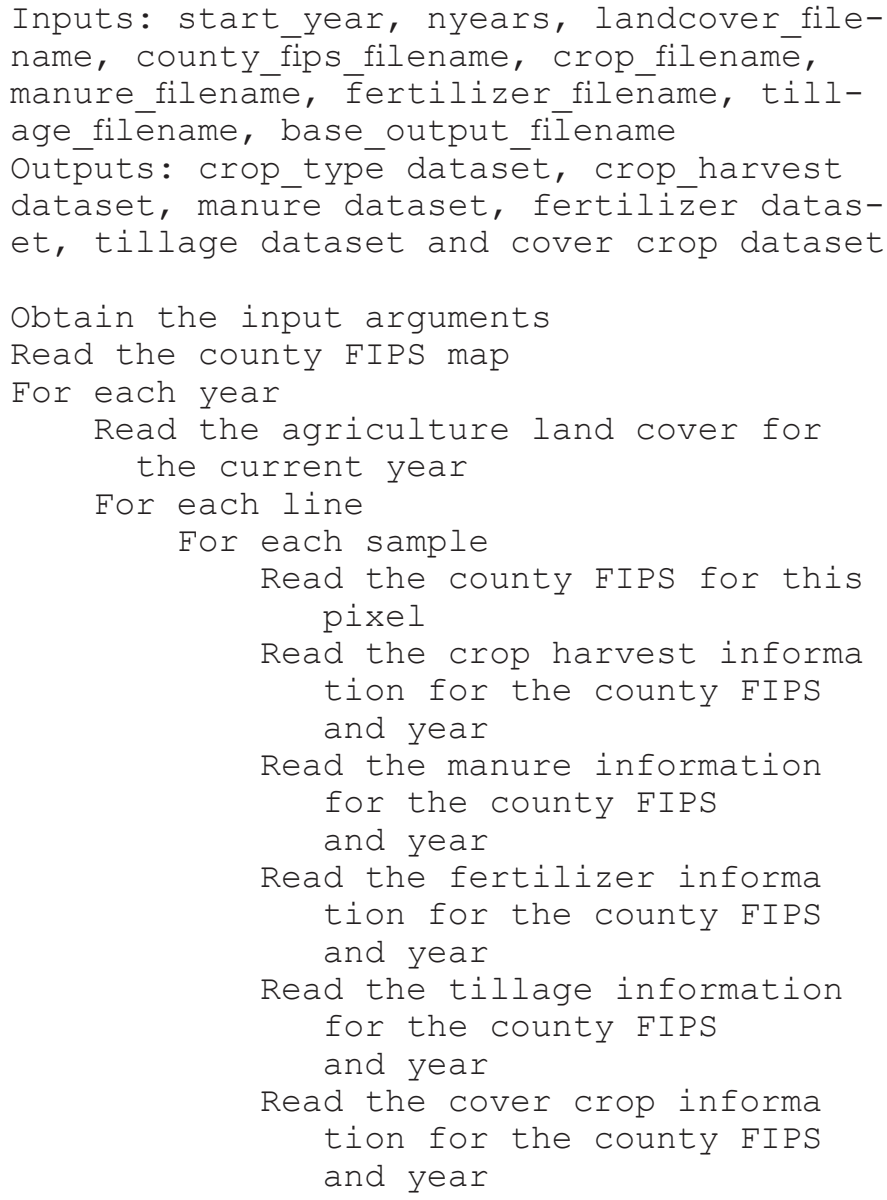




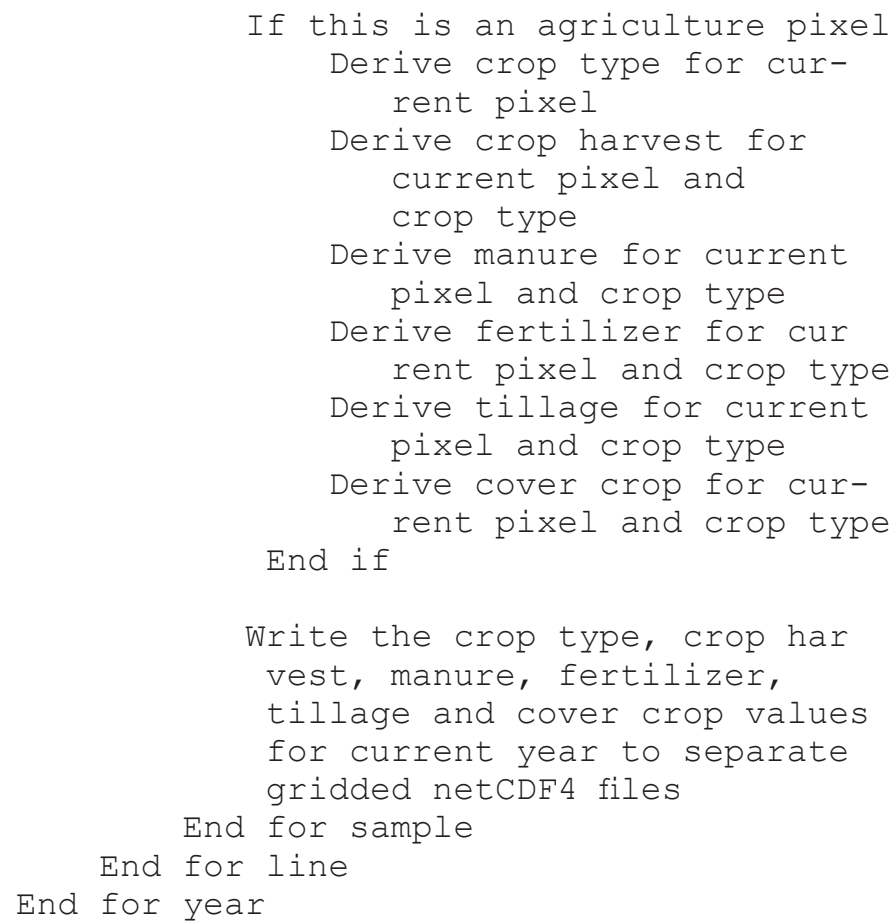

The land cover and gridded county FIPS datasets are the key inputs, in addition to the crop harvest, manure, fertilizer, tillage, and cover crop tables. A C-based application has been developed by the LandCarbon team, using the main algorithm and the algorithms described in the Crop Type, Crop Harvest, Manure, Fertilizer, Tillage Type, and Cover Crop sections, to generate derived crop management grids for the historic and A1B, A2, B1, and B2 future scenarios. These derived grids are generated for each of the ecoregions or regional study areas for each of the years being processed by the LandCarbon model.

\section{Crop Type}

The crop harvest data used by the LandCarbon project include the county FIPS, year, total acres planted, total acres harvested and yield for each crop and practice type within the county. It includes the percentage of total acres harvested and the converted yield for each crop. Crop types and practice types for crop harvest data for the represented crop types and practice types in the crop harvest table are shown in tables 1 and 2 in the appendix. The table 1 and 2 crop harvest values, along with the gridded county FIPS map, allows for a gridded crop type dataset to be derived for each of the agriculture pixels.

To derive the crop type, the percent of composition (total acres harvested) for each crop (table 1 in the appendix) was used. Based on a random number, the crop type is returned once the accumulated percent of composition exceeds the random number. The total crop practice was used to obtain the crop harvest data values for the current county FIPS and year.
Inputs: percent composition for all crops from crop harvest data for the current county and year

Generate random number, $r$ (float from 0.0 to 1.0$)$

Loop through the represented crop types

Accum percent = Accum percent + percent composition of current crop If Accum percent $>=r$ then Return current crop type End if

End loop

There are cases in the crop harvest data where the total accumulated percentage of composition was zero, therefore, no valid data were provided for that county FIPS and year. In this case, the user is asked to define a representative county FIPS value to be used [for example, the representative county used for Ecoregion 9.2 is Wright County, Iowa (county FIPS of 19197); Ecoregion 9.3 is Stark County, North Dakota (county FIPS of 38089); and Ecoregion 9.4 is Gove County, Kansas (county FIPS of 20063)]. Another option would be to use values for the current FIPS and a representative year, however, this project used the representative county FIPS versus the need to come up with a potentially different representative year for various counties. The crop type (and all other management data) is then derived using the crop harvest information from the representative county instead of the actual county for the current pixel.

The future scenario values for the crop harvest data are provided in 5-year increments instead of yearly increments. When processing the future scenarios, the crop harvest values are interpolated as needed to produce an annual derived crop type dataset.

The crop type data output is a three-dimensional product where each layer represents a year of data. The basis of the crop type product is the land cover dataset, and the crop type is then derived for agriculture class pixels. Therefore, the actual output pixel values are the same as the land cover dataset for non-agriculture pixels. See table 3 in the appendix for the land cover class values and associated class meanings. The agriculture pixels (currently a class value of 11) contain a value that represents the crop type (table 1 in the appendix) plus an offset of 100. This offset was added so that the crop type values could be distinguished from the land cover classes. Therefore, any pixel value greater than or equal to 100 represents an agriculture pixel. That pixel value minus 100 then represents the derived crop type. An example of the derived crop type data for 2000 is provided in figure 1 .

\section{Crop Harvest}

The crop harvest value is a simple flag of one or zero to represent whether the crop was harvested. The crop harvest value is only derived for agriculture pixels, and is based on 


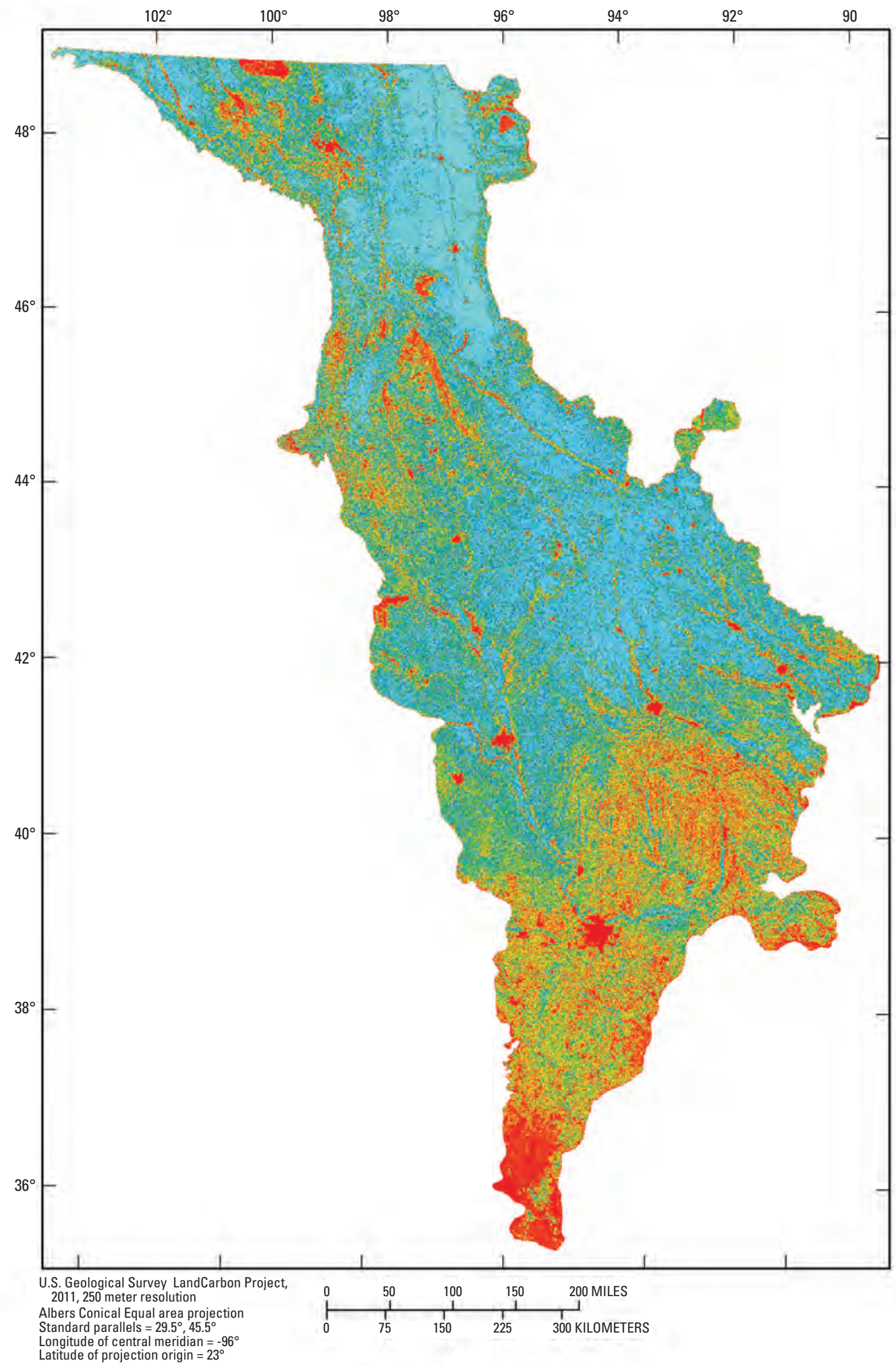

Figure 1. Derived crop type for Ecoregion 9.2. The red pixels represent non-agriculture areas. The yellow, green, and blue pixels represent agriculture areas of various derived crop types (tables 1 and 3 in the appendix). 
the derived crop type for the current pixel. To derive the crop harvest value, the planted and harvested acres for each crop (table 1 in the appendix) were used. The planted and harvested values are obtained from the crop harvest table described in the Crop Type section. The probability harvested is computed using the fraction of harvested acres to planted acres. Based on a random number, the crop was harvested if the probability harvested is larger than the random number. Otherwise the crop was not harvested. The total crop practice was used to obtain the crop harvest data values for the current county FIPS and year.

Inputs: planted acres and harvested acres values for derived crop type from the crop harvest data for the current county and year

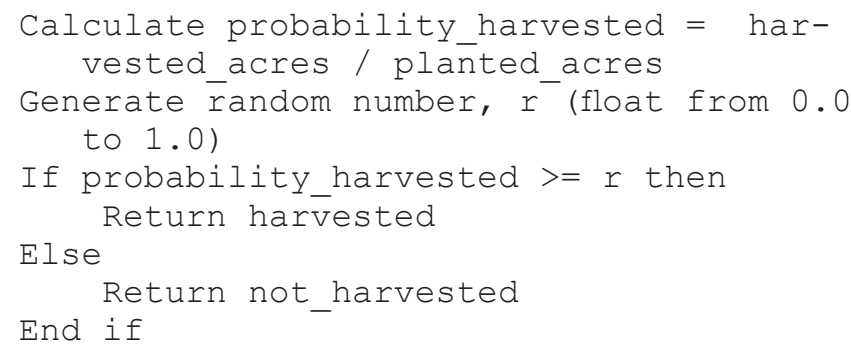

The LandCarbon project determined that the planted acres in a few counties and years were not reliable. In the event that the planted acres value was zero and the harvested acres value was nonzero, the probability harvested was set to 1.0. Furthermore, when working with the future scenario with crop harvest data, the harvested acres values were the only variables projected. Therefore, the planted acres values were not available (that is, equal to 0.0 ). The algorithm was modified to use the average of the last five years from the historic crop harvest planted acres for the projected planted acres when processing the future scenario data. As specified with the crop type, the future scenario areas and amounts for the crop harvest data are provided in 5-year increments instead of yearly increments. When processing the future scenarios, the crop harvest areas are interpolated as needed to produce an annual derived crop harvest dataset.

The crop harvest data output is a three-dimensional product where each layer represents a year of data. The actual pixel values are either 0 (not harvested) or 1 (harvested). Pixels outside of the ecoregion and pixels that are non-agriculture pixels are considered fill pixels. An example of the derived crop harvest data for 2000 is provided in figure 2.

\section{Manure}

The manure data value represents the amount of manure applied per unit area, and is based on the derived crop type for the current pixel. To derive the manure value, only the manure dataset is used. The manure data used by the LandCarbon project include the state FIPS, year, total planted area, percentage of planted area treated with manure, the amount of manure applied, rate of manure applied, rate of Nitrogen in manure applied, and rate of Carbon in manure applied for each crop type within the state. These manure values along with the gridded county FIPS map, allows for a gridded manure dataset to be derived for each of the agriculture pixels.

The manure value is computed using the percent of planted area treated with manure for the derived crop. Based on a random number, manure is considered to be applied if the percentage exceeds the random number. The manure values returned are the rate of carbon in manure applied and the rate of nitrogen in manure applied for the current crop type, state FIPS and year.

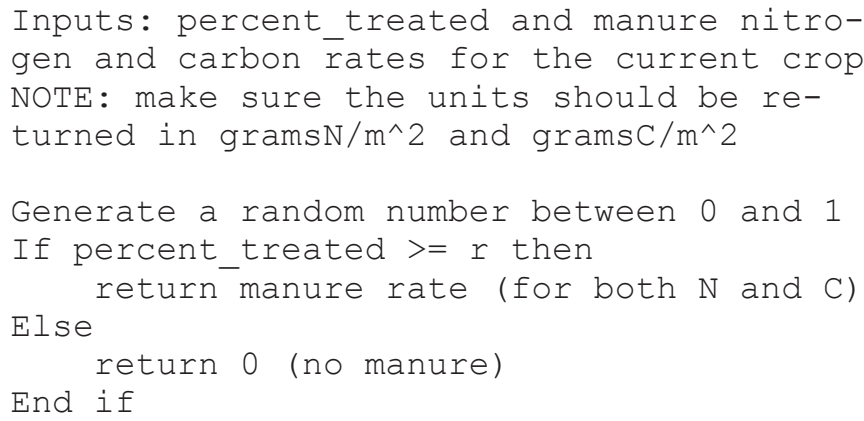

Looking at the represented crops for crop harvest and manure data (tables 1 and 4 in the appendix), there is a difference in the crops represented for each dataset. Crop type is derived using the crop harvest data, however there are many crops from that dataset (for example, beans, canola, flaxseed, and other similar crops) not represented in the manure dataset. If the particular crop type is not represented, then the winter wheat crop type is used to derive the manure value since it typically offers average management values versus outlier values. For example, if the derived crop type for the current pixel is rye, then manure data will be read and processed for the winter wheat crop type. The manure dataset also contains crops that are a superset of crops represented in the crop harvest data (that is, corn in the manure dataset and grain corn or silage corn in the crop harvest dataset). In this case, the superset crop type is used. Therefore, if the derived crop type is grain corn, then the corn crop type is used to derive the manure value. These crop type "mismatches" occur with the fertilizer and tillage data as well. The same solutions apply, except that wheat is used for the default crop for fertilizer data, since winter wheat is not represented.

As with the crop harvest data, the future scenario areas, amounts and rates for the manure data are provided in 5-year increments instead of yearly increments. When processing the future scenarios, the manure areas and rates are interpolated as needed to produce an annual derived manure dataset.

The output manure data is a three-dimensional product where each layer represents a year of data. The manure pixel 


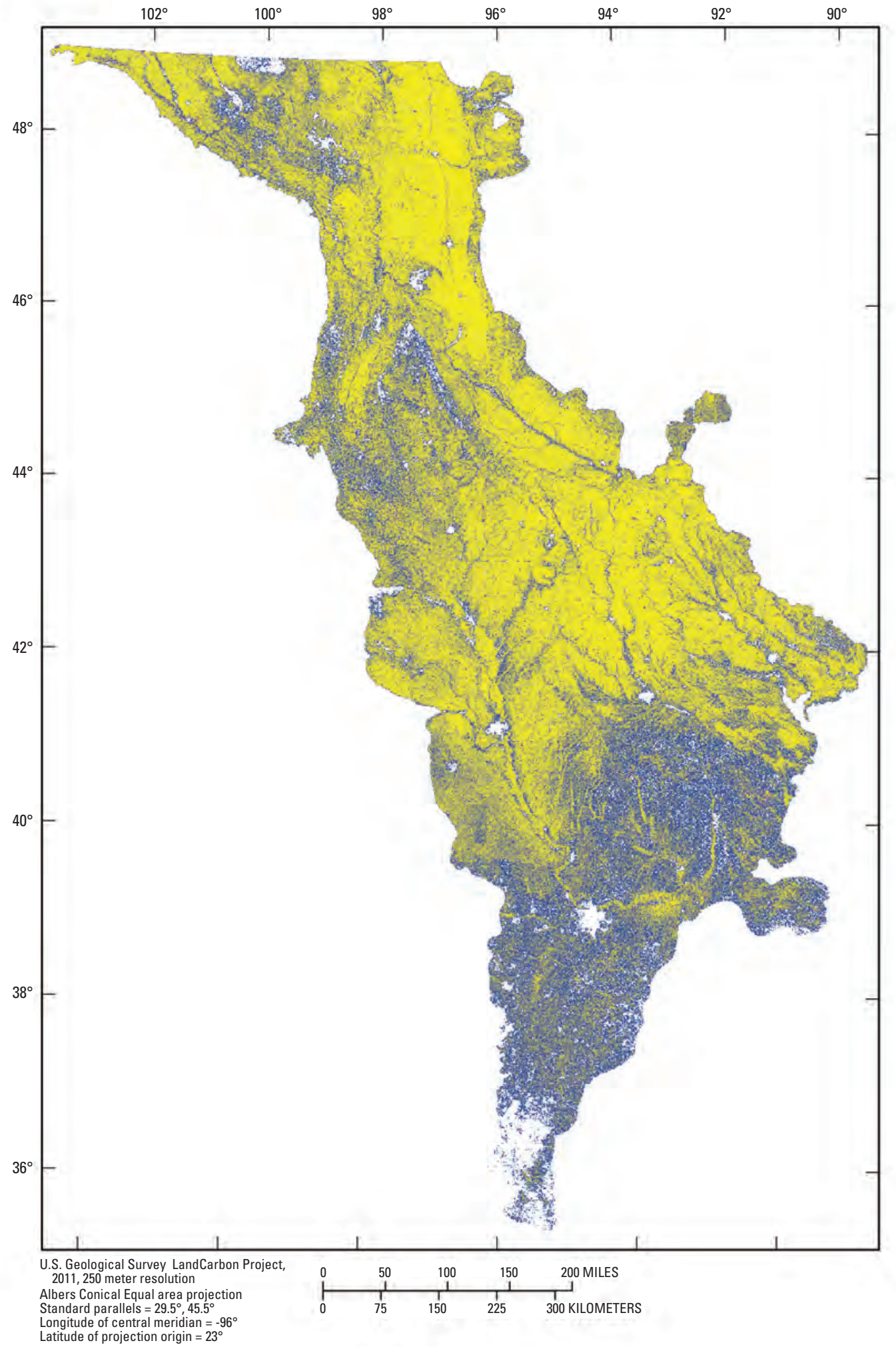

Figure 2. Derived crop harvest for Ecoregion 9.2. Gray pixels represent unharvested pixels and yellow pixels represent harvested pixels. 
values are in grams per meter squared. Pixels outside of the ecoregion and pixels that are non-agriculture pixels are considered fill pixels. An example of the derived manure data for 2000 is provided in figure 3 .

\section{Fertilizer}

The fertilizer data value represents the amount of nitrogen applied per unit area, and is based on the derived crop type for the current pixel. To derive the fertilizer value, the crop harvest and the fertilizer datasets are used. The planted and harvested values are obtained from the crop harvest table described in the Crop Type section. The table of fertilizer data used by the LandCarbon project includes the state FIPS, year, total planted area with fertilizer applied, percentage of total area with each nutrient, rate of application for each nutrient, and total nutrient amount applied for each crop type within the state. Crop types used for fertilizer data are shown in table 5 in the appendix, and table 6 in the appendix shows the represented nutrient types for fertilizer data. These crop harvest and fertilizer values along with the gridded county FIPS map, allow for a gridded fertilizer dataset to be derived for each of the agriculture pixels. The fertilizer value returned is the amount of nitrogen fertilizer applied per unit area for the current crop type, state FIPS and year.

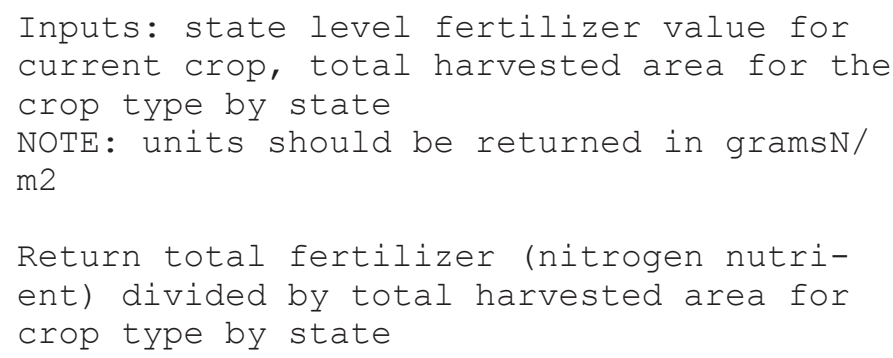

Looking at the represented crops for crop harvest and fertilizer data (tables 1 and 5 in the appendix), there is a difference in the crops represented for each dataset. The differences in represented crop types are handled the same as for the manure dataset, except the default crop type for fertilizer is wheat since it typically offers average fertilizer values of the available crop types versus outlier values.

The algorithm derives the fraction of the total fertilizer used by the harvested area. The fertilizer dataset contains the total nitrogen applied and the crop harvest data contains the total harvested area per crop. However, this total harvested area does not represent total harvested area where nitrogen was applied. To obtain an estimate of the total harvested area with nitrogen applied, the fraction of planted area with nitrogen applied to total planted area for this crop was calculated. That planted fraction was applied to the total harvested area of the crop to obtain the approximate harvested area with nitrogen applied.

When using the total planted and harvested area from the crop harvest data, those values are represented at the county level; however, fertilizer data are represented at the state level. Therefore, the total planted and total harvested areas were summed from each county per crop to obtain a state level representation of total planted and harvested area. Similarly, all the subsets of the fertilizer crop type in the crop harvest data need to be summed into this total, if applicable. For example, when processing the wheat fertilizer crop type, winter wheat, spring wheat and durum wheat values all need to be accumulated for each county in the state. In addition, the crop harvest area units are in acres, whereas the fertilizer area units are in 1,000 square meters, therefore a unit conversion of acres to square meters is needed. Finally, the future scenario areas and amounts for the fertilizer data are provided in 5-year increments instead of yearly increments. When processing the future scenarios, the crop harvest areas, fertilizer areas, and amounts are interpolated as needed to produce an annual derived fertilizer dataset.

The fertilizer data output is a three-dimensional product where each layer represents a year of data. The fertilizer pixel amounts are in grams of nitrogen per meter squared. Pixels outside of the ecoregion and pixels that are non-agriculture pixels are considered fill pixels. An example of the derived fertilizer data for 2000 is provided in figure 4.

\section{Tillage Type}

The tillage type is derived only for agriculture pixels, and is based on the derived crop type for the current pixel. The table of tillage data used by the LandCarbon project includes the state FIPS, year, total planted area tilled, total percentage of residue for all tilled areas, planted area for each tillage type, and percentage of residue for each tillage type for each crop type within the state. Crop types and tillage types for the represented crop types and represented tillage types in the tillage table are shown in tables 7 and 8 in the appendix. These tillage values along with the gridded county FIPS map, allows for a gridded tillage type dataset to be derived for each of the agriculture pixels.

The tillage algorithm accumulates the planted area for each of the tillage types. The fraction of each tillage type is calculated by dividing the planted area for each tillage type by the accumulated planted area. Based on a random number, each tillage fraction is accumulated until the sum exceeds the random number. The tillage fraction that allows the sum to exceed the random number is the tillage type returned for the current crop type, state FIPS and year. 


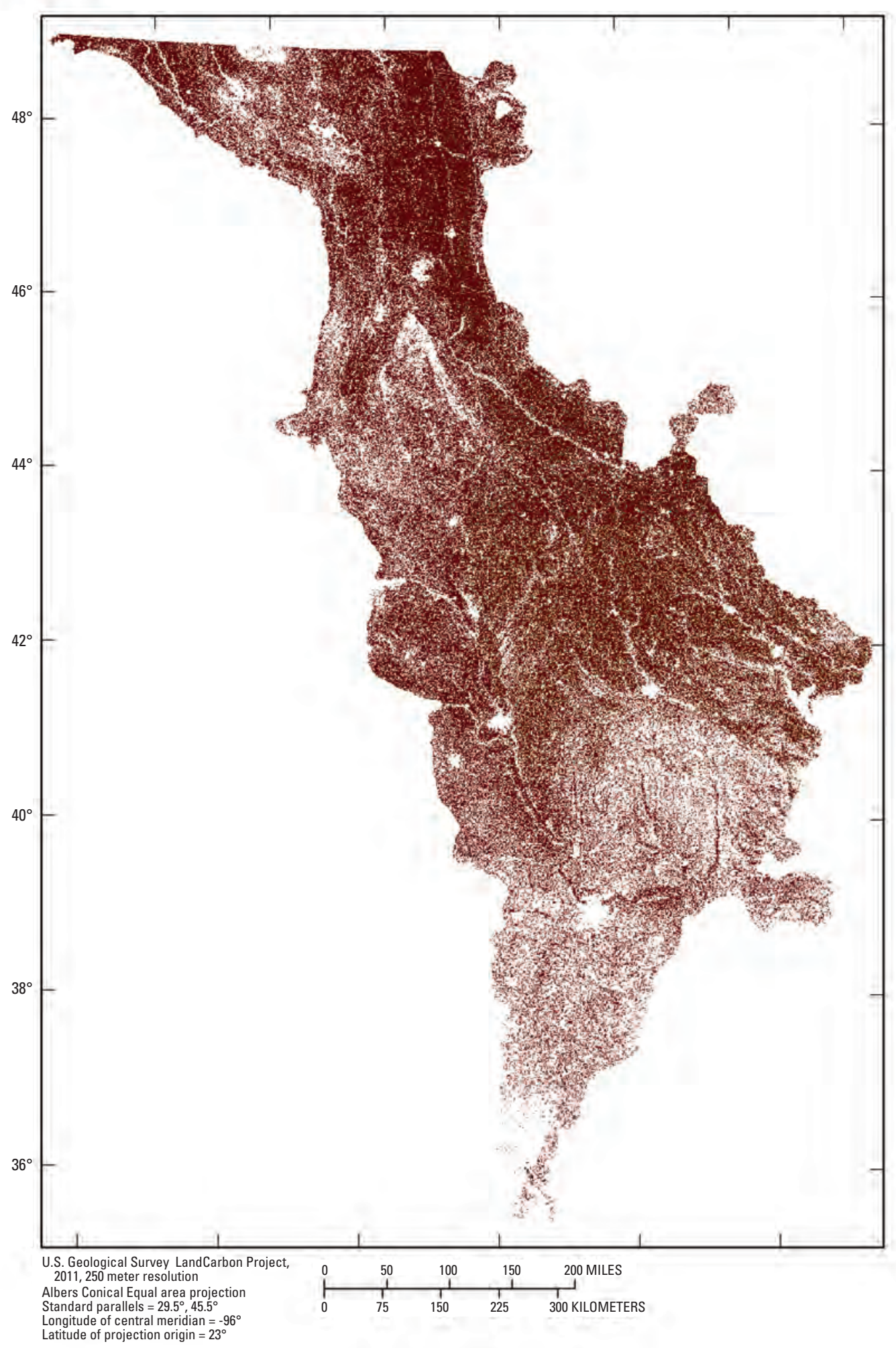

Figure 3. Derived manure Carbon rates for Ecoregion 9.2. Brown values represent pixel areas where no manure was applied. Yellow and green pixel values represent the derived manure applied in grams of carbon per meter squared, with rates up to 517 grams per meter squared. 


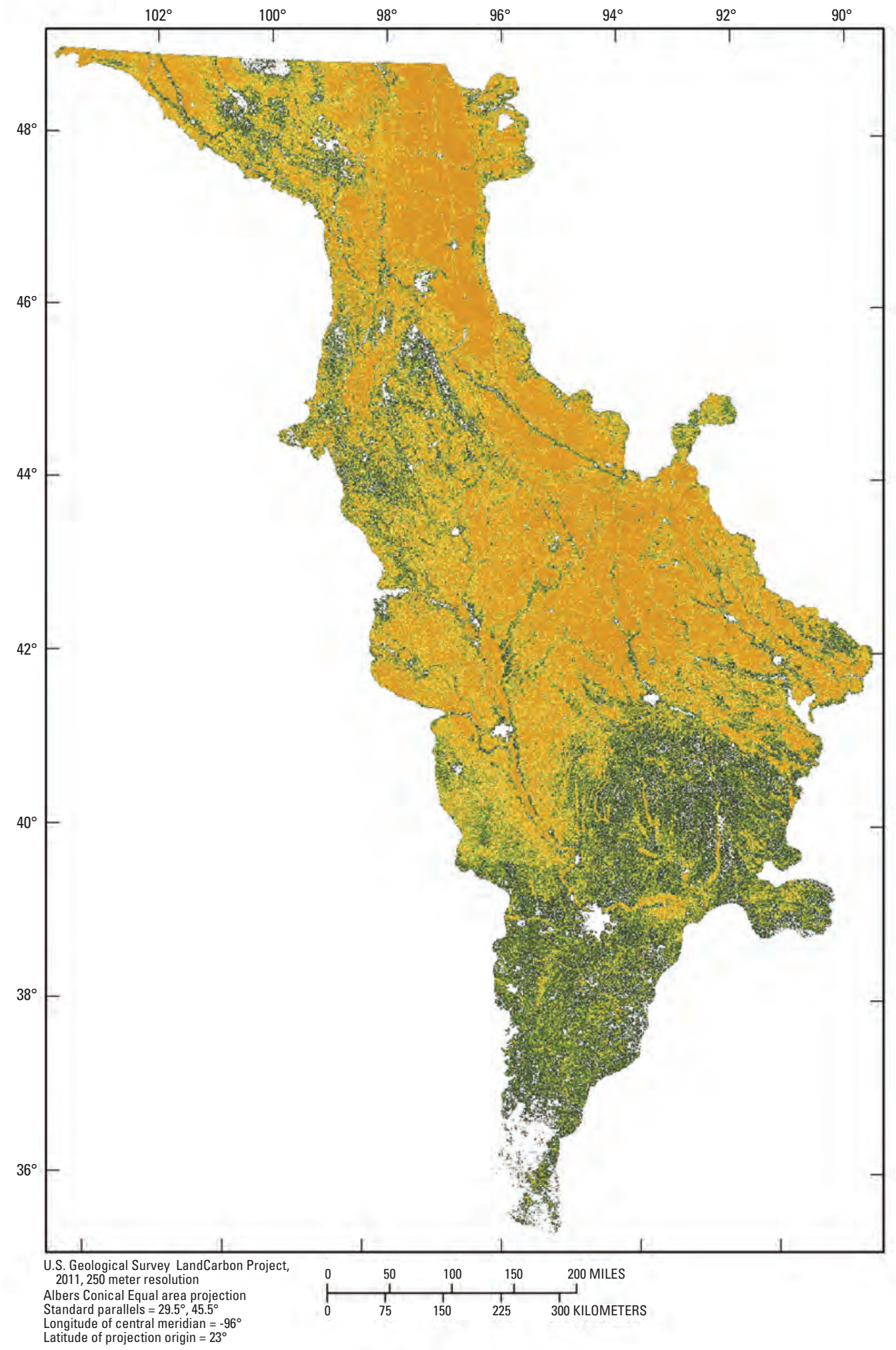

Figure 4. Derived fertilizer rates for Ecoregion 9.2. Green pixels represent areas where no fertilizer was applied. Light to deep orange pixel values represent the derived fertilizer amounts of nitrogren applied in grams of nitrogen per meter squared, in order of increasing rates up to 18 grams per meter squared. 


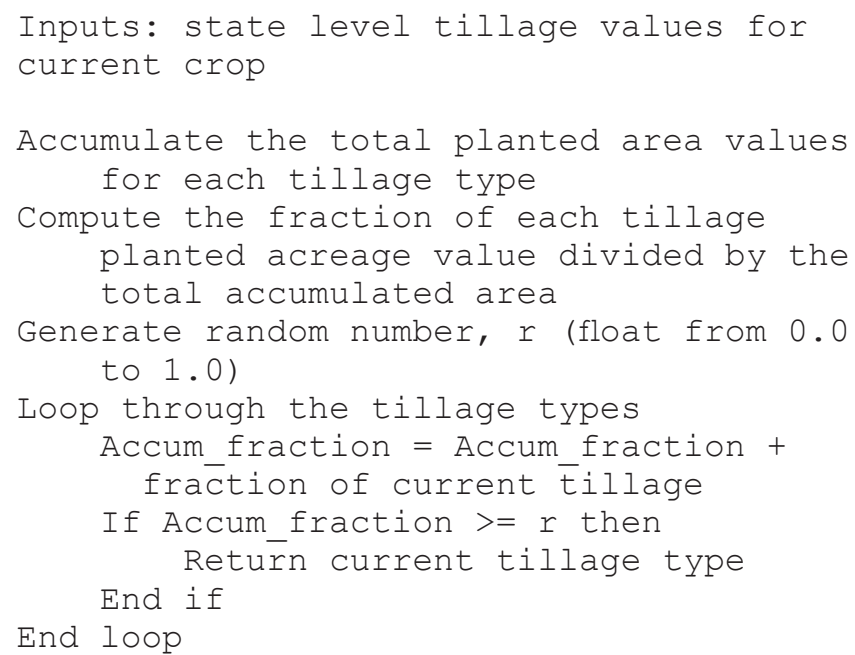

Looking at the represented crops for the crop harvest and tillage data (tables 1 and 7 in the appendix), there is a difference in the crops represented for each dataset. The differences in represented crop types are handled the same as for the manure dataset, with winter wheat being the default crop type since it typically offers average tillage values of the available crop types versus outlier values.

Unlike the other management products, projection coefficients for the tillage data were not available for the IPCC SRES scenarios. To allow tillage types to be derived for the future scenarios, an average of the last five years of historic tillage data was used to represent each year in the future scenario tillage data.

The tillage type data output is a three-dimensional product where each layer represents a year of data. The pixel values represent the derived tillage type (table 8 in the appendix) for the agriculture pixels. Pixels outside of the ecoregion and pixels that are non-agriculture pixels are considered fill pixels. An example of the derived tillage type data for 2000 is provided in figure 5 .

\section{Crop Cover Type}

Like all the other variables, the cover crop is only derived for agriculture pixels and is based on the derived crop type for the current pixel. The table of cover crop data used by the LandCarbon project is a single representation of historic data and includes the state FIPS, percentage of crop area with a cover crop, the percentage of the cover crop that is rye, and the percentage of the cover crop that is winter wheat. Cover crops are represented in this dataset only for corn, cotton, and soybeans. Therefore only corn, cotton, and soybeans can be transitioned to a cover crop. Rye and winter wheat are the only two types of cover crops reported in the USDA data. These cover crop percentages, along with the gridded county FIPS map, allow for a gridded cover crop type dataset to be derived for each of the agriculture pixels.
The cover crop algorithm first determines if a cover crop exists, based on a random number. If the percentage of crop area with a cover crop is larger than the random number, then a cover crop will be represented in the derived data. Otherwise no cover crop is represented for that pixel. To derive the particular cover crop type, another random number is used to compare to the percentage of rye and winter wheat as the cover crop for the current pixel. A value of no cover crop, rye or winter wheat will be returned for the current crop type and state FIPS.

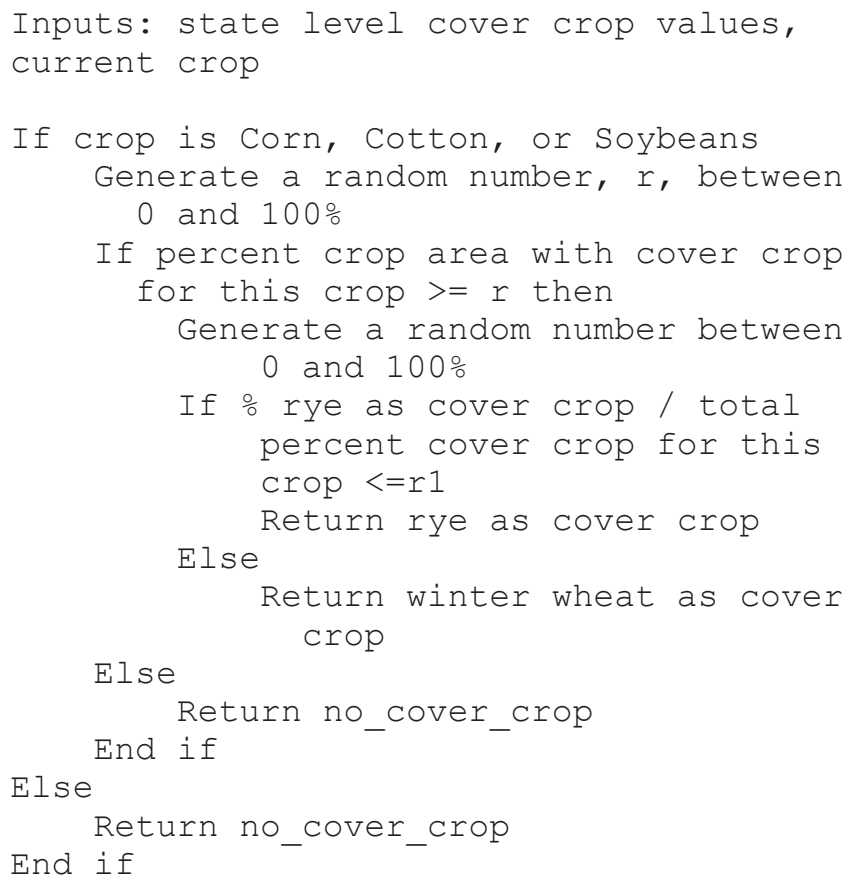

The output cover crop data output is a three-dimensional product where each layer represents a year of data. The pixel values represent the derived cover crop (table 9 in the appendix) for the agriculture pixels. Pixels outside of the ecoregion and pixels that are non-agriculture pixels are considered fill pixels. An example of the derived cover crop data for 2000 is provided in figure 6 .

\section{Special Considerations}

Processing this immense amount of data for each pixel in the ecoregion takes some time. Heavy input/output from data files is expensive in processing time, as is computing the state averages and 5-year averages. The $\mathrm{C}$-based version of the derived grids application developed by the LandCarbon team has gained substantial efficiency by implementing a couple of key elements. First, when the management data are read for the current county ID or state ID, the values are read for all the represented crops, nutrients, and tillage types in the dataset. This eliminates the need to reread the management data as the 


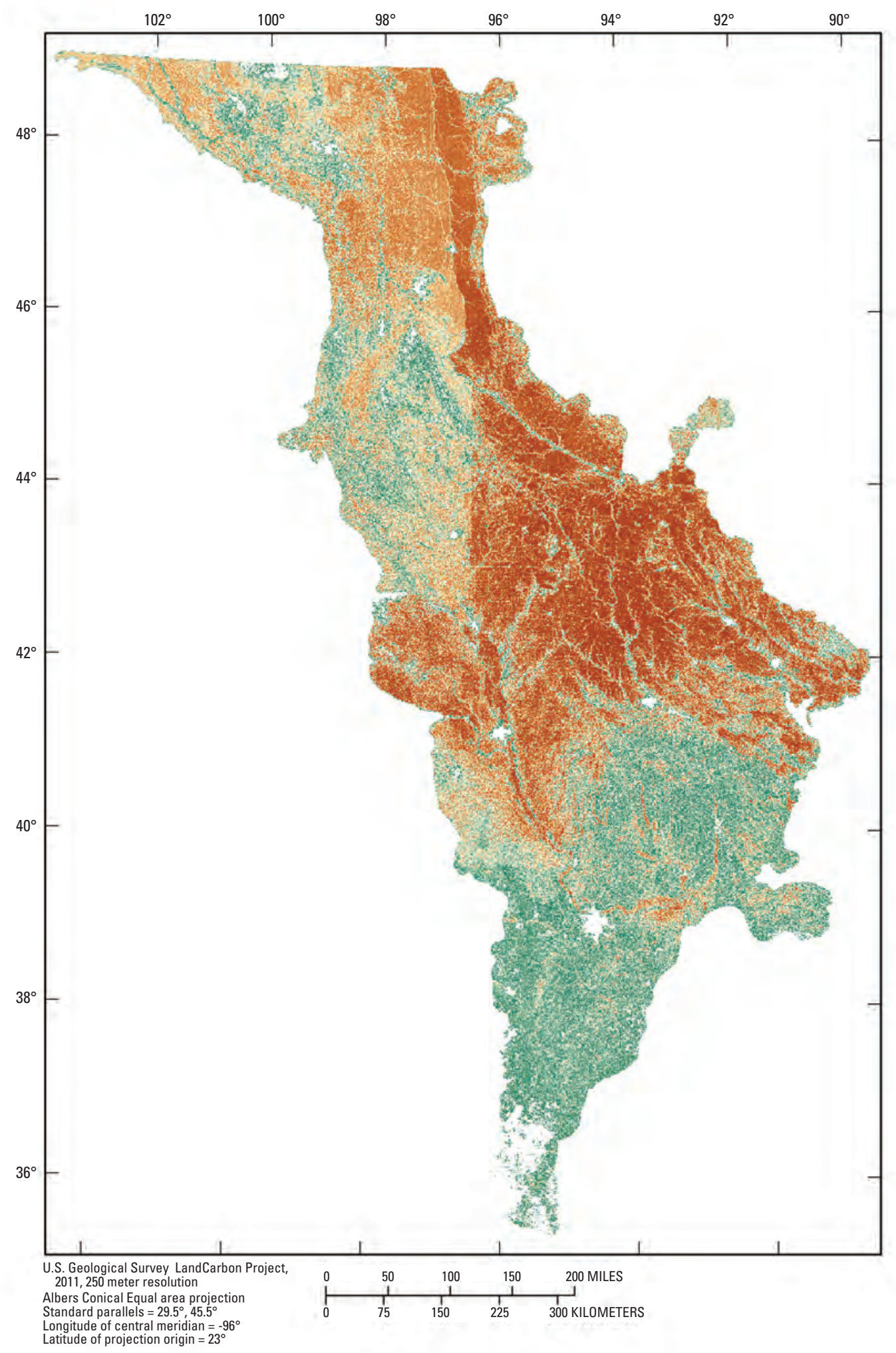

Figure 5. Derived tillage types for Ecoregion 9.2. Values represent the derived tillage types as defined in table 8 in the appendix. Deep brown areas represent conventional tillage and mulch tillage practices. Moderate brown areas represent mulch tillage and no tillage practices. Light brown areas represent reduced tillage practices. Green shades represent area where no tillage data were available or areas where tillage was not applied because of non-agriculture landcover. 


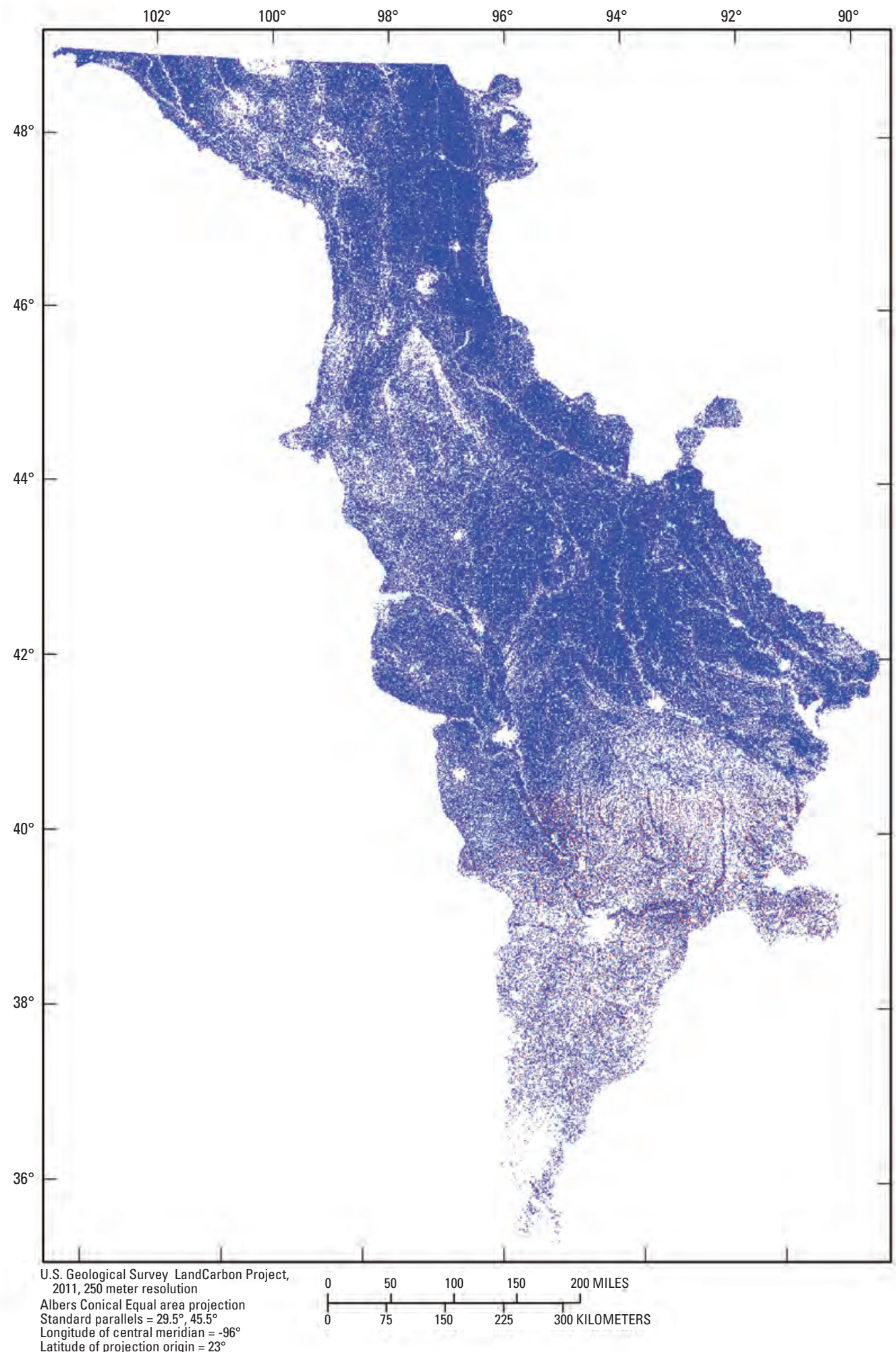

Figure 6. Derived cover crop for Ecoregion 9.2. Blue pixels represent area where no cover crop was used. Red pixels represent the winter wheat cover crop as defined in table 9 in the appendix. Rye cover crop is not used in this ecoregion. 
crop type changes from pixel to pixel. Second, the previous county and state ID are stored for each pixel. As the application loops from pixel to pixel, the same management data often can be reused since adjacent pixels are usually from the same county or state or both. This further eliminates the need to reread data and compute the 5 -year averages.

In addition, static variables are used to keep track of the index and step values are used when handling the interpolation of each crop type for all future scenario management datasets. This eliminates the need to recompute the interpolation step and index values for each pixel within the same county or state or both. Lastly, the output data values are written 1 year at a time for each management type, to minimize the number of writes that occur. A verbose flag allows the user to obtain processing information as desired and status information (10 percent, 20 percent, ... 100 percent) is written for each year in the dataset.

\section{References Cited}

Integrated Model to Assess the Global Environment (IMAGE), 2006, Integrated modelling of global environmental change-An overview of IMAGE 2.4 (C): Netherlands Environmental Assessment Agency, no. 500110002, 228 p. Publication accessed August 16, 2011 at http://www.rivm.nl/ bibliotheek/rapporten/500110002.pdf.

U.S. Department of Agriculture, Economic Research Service \& Agricultural Resource Management Survey, 2011a, ARMS Farm Financial and Crop Production Practices-Tailored Reports: database accessed August 16, 2011 at http:// www.ers.usda.gov/Data/ARMS/app/.

U.S. Department of Agriculture, Economic Research Service, 2011b, Fertilizer Use and Price: database accessed August

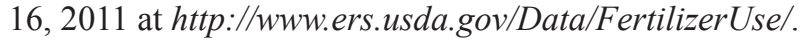

U.S. Department of Agriculture, National Agricultural Statistics Service, 2011c, Quick Stats: database accessed August 16, 2011 at http://www.nass.usda.gov/QuickStats. 


\section{Appendix}


Table 1. Crop types for crop harvest.

\begin{tabular}{cl}
\hline ID & \multicolumn{1}{c}{ Name } \\
\hline 0 & Barley \\
1 & Beans \\
2 & Canola \\
3 & Corn, grain \\
4 & Corn, silage \\
5 & Cotton \\
6 & Flaxseed \\
7 & Forage \\
8 & Hay \\
9 & Lentils \\
10 & Sorghum, silage \\
11 & Oats \\
12 & Peanuts \\
13 & Peas \\
14 & Potatoes \\
15 & Rice \\
16 & Rye \\
17 & Safflower \\
18 & Sorghum \\
19 & Soybeans \\
20 & Sugarbeets \\
21 & Sugarcane \\
22 & Sunflowers \\
23 & Sweet corn \\
24 & Tobacco \\
25 & Whematoes \\
26 & Wheat, spring \\
27 & \\
\hline &
\end{tabular}

Table 2. Practice types for crop harvest data.

\begin{tabular}{cl}
\hline ID & \multicolumn{1}{c}{ Name } \\
\hline 0 & Total crop \\
1 & Irrigated \\
2 & Non-irrigated \\
3 & Non-irrigated, continuous cropping \\
4 & Non-irrigated, following summer fallow \\
5 & Following another crop (double cropping) \\
6 & Not following another crop \\
\hline
\end{tabular}

Table 3. Land cover classes used in crop type data.

\begin{aligned} & \hline ID \multicolumn{1}{c}{ Name } \\ & \hline 1 Water \\ & 2 Developed \\ & 3 Mechanically disturbed \\ & 5 Mining \\ & 6 Barren \\ & 7 Deciduous forest \\ & 8 Evergreen forest \\ & 9 Mixed forest \\ & 10 Shrubland \\ & 11 Grassland \\ & 12 Agriculture \\ & 13 Hay or pasture \\ & 14 Woody wetlands \\ & 15 Herbaceous wetlands \\ & \hline\end{aligned}

Table 4. Crop types for manure data.

\begin{tabular}{cl}
\hline ID & \multicolumn{1}{c}{ Name } \\
\hline 0 & Barley \\
1 & Corn \\
2 & Cotton \\
3 & Oats \\
4 & Peanuts \\
5 & Soybeans \\
6 & Wheat, spring \\
7 & Wheat, durum \\
8 & Wheat, winter \\
\hline
\end{tabular}

Table 5. Crop types for fertilizer data.

\begin{tabular}{ll}
\hline ID & Name \\
\hline 0 & Corn \\
1 & Cotton \\
2 & Soybeans \\
3 & Wheat \\
\hline
\end{tabular}

Table 6. Nutrient types for fertilizer data.

\begin{tabular}{cl}
\hline ID & Name \\
\hline 0 & Nitrogen \\
1 & Phosphate \\
2 & Potash \\
\hline
\end{tabular}


Table 7. Crop types for tillage data.

\begin{aligned} & \hline ID \multicolumn{1}{c}{ Name } \\ & \hline 0 Barley, feed \\ & 1 Barley, malted \\ & 2 Corn \\ & 3 Cotton \\ & 4 Oats \\ & 5 Peanuts \\ & 6 Rice \\ & 7 Sorghum \\ & 8 Soybeans \\ & 9 Wheat, spring \\ & 10 Wheat, winter \\ & \hline\end{aligned}

Table 8. Tillage types for tillage data.

\begin{aligned} & \hline ID \multicolumn{1}{c}{ Name } \\ & \hline 0 Conventional tillage \\ & 1 Mulch tillage \\ & 2 No tillage \\ & 3 Reduced tillage \\ & 4 Ridge tillage \\ & 5 Unknown tillage \\ & 99 Tillage N/A ${ }^{1} \\ &$\hline\end{aligned}

${ }^{1}$ This class denotes that no tillage data were available for this state and crop, therefore it is unknown if tillage practices were used.

Table 9. Cover crop types for cover crop data.

\begin{tabular}{cl}
\hline ID & \multicolumn{1}{c}{ Name } \\
\hline 0 & No cover crop \\
1 & Rye cover crop \\
2 & Winter wheat cover crop \\
\hline
\end{tabular}


Publishing support provided by:

Rolla Publishing Service Center

For more information concerning this publication, contact:

U.S. Geological Survey Earth Resources Observation and Science (EROS) Center

47914 252nd Street

Sioux Falls, South Dakota, 57198

(605) 594-6151

gmted2010@usgs.gov

Or visit the EROS Center web site at:

http://eros.usgs.gov/ 



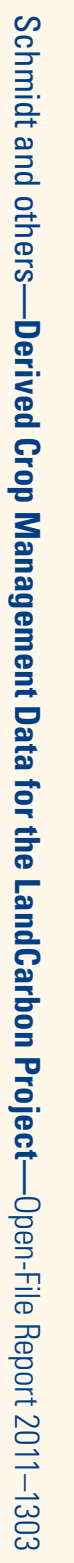

